\title{
PANORAMA EDITORIAL DA LITERATURA AFRO-BRASILEIRA ATRAVÉS DOS GÊNEROS ROMANCE E CONTO
}

Luiz Henrique Silva de

Oliveira*

Fabiane Cristine Rodrigues**

RESUMO: Este trabalho propõe-se a analisar as dinâmicas editoriais e sociais que viabilizaram o surgimento, a produção e a circulação de livros de contos e romances escritos por autores afro-brasileiros. Para isso, procuramos resgatar as publicações individuais destes autores. Posteriormente, tecemos reflexões sobre: a relação entre autoria e quantidade de publicações individuais; Os periodos e a frequencia destas publicacões; a quantidade de publicações autorais por casas editoriais; e a distribuição espacial de tais publicações pelo Brasil.

PALAVRAS CHAVE: produção editorial; literatura afro-brasileira; conto; romance.

* henriqueletras@yahoo.com.br

Doutor em Teoria da Literatura e Literatura Comparada pela UFMG. Professor do Programa de Pós-Graduação em Estudos de Linguagen e da Graduação em Letras - Tecnologias de Ediça do CEFT-MG. Coordenador do Grupo de Estudos Produção Editorial Luso Afro Brasileira (PELAB)

* fabby-ane@hotmail.com

Mestranda em Estudos de Linguagens pelo CEFET-MG. Membro do Grupo de Estudos Produção Editorial Luso Afro Brasileira (PELAB).

ABSTRACT: This work proposes to analyze the editorial and social dynamics that enabled the emergence, production and circulation of tales and novels written by Afro-Brazilian authors. To make this possible, we search the individual publications of these authors. Subsequently, we made reflections on: the relationship between authorship and the number of individual publications; The periods and the frequency of these publications; The numThe peiods and the frequency of these publications; The number of copyrighted publications by publishing houses; And the

KEYWORDS: editorial production; afro-Brazilian literature; tale; novel. 
1. Disponível em: <http://www.letras. ufmg.br/literafro/autores $>$.

2. Núcleo de Estudos Interdisciplinares da Alteridade da Faculdade de Letras da UFMG.

3. Grupo de Estudos Produção Editorial Luso Afro Brasileira CEFET-MG.

\section{INTRODUÇÃO}

Os levantamentos feitos no projeto de pesquisa História editorial da literatura afro-brasileira (1859-2015): romance e conto, coordenado pelo professor Dr. Luiz Henrique da Silva Oliveira, somados aos materiais disponíveis no Portal Literafro $^{1}$ e outras fontes, como os bancos de dados do NEIAUFMG $^{2}$ e do PELAB/CEFET-MG, ${ }^{3}$ possibilitaram o surgimento deste estudo, dedicado às dinâmicas que caracterizaram o surgimento de livros individuais de contos e romances afro-brasileiros. Estas fontes compuseram uma espécie de "inventário" da produção literária de autores negros brasileiros em diversos gêneros.

A fim de entender a dinâmica editorial (e social) que possibilitou o surgimento da vertente literária em questão na cena nacional, iniciamos o levantamento dos contistas e romancistas negros e suas obras individuais no intervalo temporal de 1859 até o primeiro semestre de 2016. A escolha por este intervalo de tempo levou em consideração o ano da primeir obra, dentre os gêneros aqui abordados, publicada por um autor negro no Brasil. Trata-se do romance Úrsula, escrito pela maranhense Maria Firmina dos Reis. Já o primeiro semestre de 2016 corresponde ao período de atualização do bancos de dados utilizados na composição deste inventário de produção literária.
Para esta proposta de panorama editorial da chamada literatura afro-brasileira, foi realizado o levantamento de autores e suas obras individuais. A partir das informações obtidas, foi possível organizar os dados e estabelecer análises divididas por temas, tais como: a relação entre autor e quantidade de publicações individuais; períodos e frequência de publicações; quantidade de publicações autorais por casa editorial; e distribuição espacial de tais publicações pelo Brasil. A pergunta motivadora deste trabalho, portanto, é: como se deu a trajetória do conto e do romance afro-brasileiros, considerando as publicações individuais dos autores?

A literatura afro-brasileira, de acordo com Eduardo de Assis Duarte, "constitui-se a partir de textos que apresentam autores, ponto de vista e temática culturalmente identificados com a afrodescendência, como fim e começo". ${ }^{5}$ Estes autores optam por um trabalho cuidadoso e específico com a linguagem, entendida como matéria literária $e$ veículo de determinadas imagens. E, além disso, os artistas preocupam-se com a formação de um público leitor sensível às questões de ordem étnica e racial.

Duarte $^{6}$ destaca aspectos que diferenciam a literatura afro-brasileira daquela que apenas trata do tema negro. ${ }^{7}$ Para o crítico, a temática tem o negro como elemento central, não como mero objeto ou acessório, mas com todo o universo que o cerca e o caracteriza como indivíduo. Evidentemente,
4. Destacar as publicações individuais, neste caso, é relevante porque o conto de autoria afro-brasileira fo amplamente difundido por meio de publicações coletivas, tais como as antologias. Maior exemplo é a série Cadernos Negros, iniciada em Nos anos pares, poemas sã publicados. Nos anos ímpares, contos.

5. DUARTE. Literatura afro-brasileira: um conceito em construção, p. 12

6. DUARTE. Literatura afro-brasileira: um conceito em construção, p. 12

7. Propõe-se chamar de negrismo a abordagem do universo afrodescendente como mero horizonte temático, como objeto. A este respeito, conferir OLIVEIRA, Luiz Henrique Silva de. Negrismo: percursos e configuraçoes em romances brasileiros do século XX 2014 
8. Nesta seção optamos por dispor os autores em ordem alfabética de seus nomes a partir da planilha de levantamento de dados utilizada neste estudo. a temática negra não reduz a criatividade do autor, tampouco lhe impõe a autocensura. A autoria leva em conta a experiência existencial do sujeito negro. Soma-se a ela o ponto de vista já que não basta apenas que o produtor do texto seja negro ou afrodescendente: ele deve se afirmar e posicionar a partir deste lugar de fala, compreendendo aspectos históricos culturais comuns a esse segmento social. Já o trabalho com a linguagem torna-se relevante pois é construída a partir de uma discursividade própria e que ressalta ritmos, entonações, opções vocabulares e, mesmo, toda uma semântica singular, empenhada muitas vezes na ressignificação de sentidos hegemônicos na língua. E, por fim, a formação de determinado público leitor, marcado pela diferença cultural e pelo anseio de afirmação identitária que compõe a faceta política do projeto literário afro-brasileiro.

A partir dessas noções, partimos para a apresentação e as análises dos dados referentes às publicações individuais de contos e romances afro-brasileiros.

\section{RELAÇÃO DE LIVROS POR AUTOR}

Os 88 livros autorais de contos afro-brasileiros, publicados entre 1839 e 2016, são de autoria de 42 escritores, sendo que o que conta com a maior quantidade de livros, Rogério Andrade Barbosa, autor predominantemente infantojuvenil, publicou 11 obras: Contos ao redor da fogueira (1990), Duula, a mulher canibal: um conto africano (2000), Histórias africanas para contar e recontar (2001), Contos africanos para crianças brasileiras (2004), Três contos da sabedoria popular (2005), Contos de encantos, seduções e outros quebrantos (2005), Outros contos africanos (2007), Contos africanos de adivinhação (2009), Histórias que nos contavam em Angola (2009), Contos de Itaparica (2010) e Contos da terra do Gelo (2012).

Em seguida, a lista traz Machado de Assis, com sete publicações: Contos fluminenses (1872), Histórias da meia-noite (1873), Papéis avulsos (1882), Histórias sem data (1884), Vária histórias (1896), Páginas recolhidas (1899) e Relíquias de casa velha (1906).

Mestre Didi publicou cinco livros: Contos negros da Bahia (1961), Contos de nagô (1962), Contos crioulos da Bahia, narrados por Mestre Didi (1976), Contos de Mestre Didi (1981) e uma reedição dos dois primeiros: Contos negros da Bahia e contos de nagô (2003).

Os autores Francisco de Paula Brito, Conceição Evaristo, Cuti, Fábio Mandingo, Muniz Sodré e Nei Lopes, por sua vez tiveram, cada um, três livros publicados, sendo eles: Revelação póstuma (1839), A mãe-irmã (1839) e O enjeitado (1839), de Paula Brito; Insubmissas lágrimas de mulheres (2011), Olho d'água (2014) e Histórias de leves enganos e parecenças (2016) de Conceição Evaristo; Quizila (1987), Negros em contos (1996)
9. Sobre a faceta afro-brasileira na literatura de Machado de Assis, consultar ASSIS, Machado de; DUARTE, Eduardo de Assis. Machado de Assis atrodescendente: escritos de Janeiro: Pallas; . 
e Contos crespos (2009), de Cuti; Salvador negro rancor (2011), Morte e vida virgulina (2013) e Muito como um rei (2016) de Fábio Mandingo; Santugri: histórias de mandinga e capoeiragem (1988), Rio, Rio (1995) e A lei do santo (2000), de Muniz Sodré; Casos crioulos (1987), 171, Lapa-Irajá - casos e enredos do samba (1999) e 20 contos e uns trocados (2006), de Nei Lopes.

Com duas publicações, podemos apontar: de Ademiro Alves (Sacolinha): 85 letras e um disparo (2006) e Manteiga de cacau (2012); de Alzira dos Santos Rufino: Qual o quê! (2006) e Alzira Rufino uma ativista feminegra (2008); de Bahia (José Ailton Ferreira): Trajetória cotidiana (1993) e Paradoxo do P.Q.P (1986); de Eustáquio José Rodrigues: Cauterizai o meu umbigo (1986) e Flor de sangue (1990); de Geni Guimarães: Leite do peito (1988) e A cor da ternura (1989); de Henrique Cunha Jr.: Negros na noite (1987) e Tear africano (2004); de Jussara Santos: De flores artificiais (2002) e Com afagos e margaridas (2006); de Lima Barreto: Histórias e sonhos (1920) Contos reunidos (2005); de Mãe Beata de Yemanjá: Caroço de dendê: a sabedoria dos terreiros (2002) e Histórias que a minha avó contava (2004); de Mãe Stella de Oxóssi: Meu tempo é agora (1993) e Òsòsi: o caçador de alegrias (2006); de Maria Helena Vargas (M. Helena Vargas da Silveira): O encontro (2000) e As filhas das lavadeiras (2002); de Raul Astolfo Marques: $A$ vida Maranhense (1905) e Natal (1908); e de Ubiratan Castro de Araújo: Sete histórias de negro (2006) e Histórias de negro (2009).
No entanto, 20 destes 42 escritores contam com apenas uma publicação autoral, sendo: Enterro (1982), de Abelardo Rodrigues; Fogo do olhar (1989), de Abílio Ferreira; Contos para nossos filhos (1896), de Antônio Gonçalves Crespo; Sertão Sinistro (s.d.), de Aristides Teodoro; Você me deixe, viu? Eu vou bater meu tambor! (2008), de Cidinha da Silva; Espelhos, miradouros, dialéticas da percepção (2011), de Cristiane Sobral; 106 falas de amor (2005), de Cyana Leahy-Dios; Só as mulheres sangram (2011), de Eliana Vieira (Lia Vieira); Malungos e milongas (1988), de Esmeralda Ribeiro; A cor errada de Shakespeare (2006), de José Endoença Martins; Sikulume \& outros contos africanos (2005), de Júlio Emílio Braz; Sete: diásporas intimas (2011), de Landê Onawalê; Desencontros (2007), de Miche Yakini; Mulher mat(r)iz (2011), de Miriam Alves; Contos de Valério Santiago (1972), de Nascimento Moraes; O carro do êxito (1972), de Oswaldo de Camargo; Fogo cruzado (1980), de Paulo Colina; As pulgas e outros contos de horror (1997), de Ramatis Jacino; Contos de cidadezinha (1996), de Ruth Guimarães; e Achados (2004), de Waldemar Euzébio Pereira.

Já os 61 romances afro-brasileiros, publicados entre 1859 2016, são de autoria de 29 escritores, sendo Machado de Assis o autor que publicou a maior quantidade de obras deste gênero: nove. São elas: Ressurreição (1872), A mão e a luva (1874), Helena (1876), Iaiá Garcia (1878), Memórias Póstumas de Brás Cubas (1881), Quincas Borba (1891), Dom Casmurro (1899), Esaú Jacó (1904) e Memorial de Aires (1908). 
10. Seu primeiro romance Recordações do escrivão Isaías Caminha, foi publicado em 1909 pela editora Clássica, na cidade de Lisboa, motivo pelo qual não foi incluído neste levantamento.
Em seguida, temos Nei Lopes, com cinco publicações: Mandingas da mulata velha na cidade nova (2009), Oiobome (2010), Esta árvore dourada que supomos (2012), A lua triste descamba (2012) e Rio Negro, 50 (2015).

O autor Lima Barreto conta com quatro romances publicados em casas editoriais brasileiras ${ }^{10}$ : Triste fim de Policarpo Quaresma (1915), Numa e Ninfa (1915), Os bruzundungas (1922) e Clara dos Anjos (1948).

Com três publicações, podemos apontar Joel Rufino dos Santos, José do Patrocínio, José Endoença Martins e Martinho da Vila, com os romances: Crônicas de indomáveis delírios (1991), Bichos da terra tão pequenos (2010) e Claros sussurros de celestes ventos (2012), de Joel Rufino dos Santos; Moto Coqueiro ou A pena de Morte (1877), Os retirantes (1879) e Pedro Espanhol (1884), de José do Patrocínio; Enquanto isso em Dom Casmurro (1993), Legbas, Exus e jararacumbah blues (2012) e $O$ dom de Casmurro (2012), de José Endoença Martins; Joana e Joanes - um romance fluminense (1999), Os lusófonos (2006) e Serra do Rola Moça (2009), de Martinho da Vila.

Com dois romances publicados podemos apontar: Ademiro Alves (Sacolinha), com Graduado em marginalidade (2005) e Estação Terminal (2010); Aline França, com A mulher de Aleduma (1981) e Negrão Dony (1978); Ana Maria Gonçalves, com Ao lado e à margem do que sentes por mim (2002) e Um defeito de cor (2006); Arlindo Veiga dos Santos, com As filhas da cabana (ou No fundo dos portões) (1921) e As filhas da cabana (ou No fundo dos portões) parte II (1923); Conceição Evaristo, com Ponciá Vicêncio (2003) e Becos da memória (2006); Muniz Sodré, com O bicho que chegou à feira (1991) e Bola da vez (1994); Oswaldo Faustino, com A legião negra (2011) e A luz de Luiz: por uma terra sem reis e sem escravos; Paulo Lins, com Cidade de Deus (1997) e Desde que o samba é samba (2012). Raymundo de Souza Dantas, com Sete palmos de terra (1944) e Solidão nos campos (1949).

Dos 29 autores de romances afro-brasileiros, 13 contam com apenas um romance publicado, sendo eles: de Alzira dos Santos Rufino, A mulata do sapato lilás (2007); de Anajá Caetano, Negra Efigênia, paixão do senhor branco (1966); de Carolina Maria de Jesus, Pedaços de fome (1963); de Eustáquio José Rodrigues, Além das águas de cor (2014); de Fausto Antônio, Exumos (1995); de Francisco Maciel, O primeiro dia do ano da peste (2001); de Márcio Barbosa, Paixões crioulas (1987); de Maria Firmina dos Reis, Úrsula (1859); de Mirian Alves, Bará - na trilha do vento (2016); de Nascimento Moraes, Vencidos e degenerados (1915); de Ramatis Jacinto, O justiceiro (1992); de Romeu Crusoé, A maldição de Canaan (1951); e de Ruth Guimarães, Água funda (1946).

Em resumo, dos 42 contistas, apenas três possuem pelo menos cinco livros de contos publicados e, dos 29 romancistas, 
11. CUTI. Literatura negro-brasileira, p. 47 .

12. Vale conferir os depoimentos de Cristiane Sobral, Mel Adún Conceição Evaristo, Débora de Almeida, Esmeralda Ribeiro e Miriam Alves dados à pesquisadora estadunidense Dawn Duke. Neles, as autoras são categóricas quanto à dificuldade de acesso do escritor negro às grandes casas editoriais. Ver DUKE, Dawn. $A$ escritora afroBelo Horizonte: Nandyala, 2016. apenas dois possuem pelo menos cinco obras publicadas. Considerando que "os discursos (todos) passam pelo poder dizê-lo" e que "o silêncio pertence à maioria que ouve e, quando muito, repete [...], falar e ser ouvido é um ato de poder" ${ }^{11}$ e levando em conta ainda que se pode dizer o mesmo sobre escrever e ser lido, tais dados sugerem um silenciamento velado em relação ao autor negro na cena editorial. Este silenciamento nem sempre está explícito, contudo, pode ser percebido tanto pela ausência de obras autorais disponíveis para o público leitor, quanto pela uniformidade do discurso que é veiculado por esta literatura quando o assunto é a circulação de livros. ${ }^{12}$ Indício deste cenário é a promulgação, em 2002, da Lei n. 10.639, a qual nasce justamente da necessidade de visibilidade da produção cultural da produção cultural afro-brasileira.

A partir dos gêneros estudados, é possível observar certa predominância de autores bissextos, ou seja, aqueles autores que publicam poucas obras, sem regularidade. Este fenômeno pode ser explicado a partir das condições destacas por Martins para o surgimento e a manutenção de uma tradição letrada especificamente negra no Brasil:

a tradição letrada exige certas condições específicas de produção e de recepção para o seu exercício, condições essas também desfavoráveis ao negro africano e seus descendentes.
A escrita carece de leitores e interlocutores. Os lugares de enunciação do escritor e os sujeitos de recepção da escrita, a maior ou menor mobilidade social e econômica dos brancos, mestiços e negros, na sociedade em geral e nos meios letrados em particular; o acesso à formação escolar e aos meios de produção, os preconceitos, discriminações e exclusões do sistema são alguns dos fatores que não podem ser relevados quando analisamos, diacronicamente, a produção literária afro-brasileira. ${ }^{13}$

As dificuldades de criação de uma tradição brasileira de contistas ou romancistas negros remontam, invariavelmente, ao regime escravista que vigorou no Brasil por mais de 300 anos, submetendo a população negra a um processo de desumanização e total privação de direitos, e às formas como se deu a "abolição" deste regime. Cabe ressaltar as proibições impostas aos negros escravizados de se alfabetizarem e frequentarem as escolas implantadas no Brasil até as vésperas da abolição, além das perseguições sofridas pelos negros que já eram alfabetizados. ${ }^{14}$ Indagamos se as perseguições sofridas pelos negros durante e após a abolição resultaram modificações profundas nas condições deste coletivo. Segundo Silva e Araújo,

apesar de a Reforma de Benjamin Constant ter como mérito o rompimento com a antiga tradição do ensino humanístico,
13. MARTINS Literatura e afrodescendência, p. 109
14. Só recentemente a produção escrita de escravizados no Brasi começa a ser estudada. Conferir, por exemplo, "A Carta da escrava Esperança Garcia do Piauí: uma narrativa precursora da literatura afro-brasileira". In Anais do XIV Congresso Internacional da ABRALIC. Disponível em: http://www.abralic.org.br/anais/ arquivos/2015_1455937376.pdf, acesso em 08 de jun. de 2016. 
15. SILVA; ARAÚJO. Da interdição escolar às ações educacionais de sucesso: escolas dos movimentos técnicas e tecnológicas, p. 70

o Decreto Nacional no 981/1890 estabeleceu, entre outras medidas centralizadoras, a ênfase na introdução da disciplina "Moral e Cívica", nítida tentativa de "normalizar" a conduta social e moral da sociedade após a libertação dos escravos. No decreto $n^{\circ}$ 982/1890 foram estabelecidas medidas proibitivas ("não será permitido aos alunos ocupar-se na escola com redação de periódicos"), punitivas ("se a agressão ou violência se realizar, o culpado será imediatamente entregue à autoridade policial e expulso da escola"), centralizadoras elitistas, como por exemplo, a nomeação dos diretores das escolas públicas pelo próprio Governo. ${ }^{15}$

A forma como o negro teve acesso à educação reforça o controle imposto ao que poderia ou não ser dito, bem como evidencia as tentativas de impedir a organização negra e as formas de manter a hegemonia e o poder aos brancos pelo domínio dos discursos produzidos por parte da sociedade. $\mathrm{O}$ negro deveria saber o suficiente para ser útil como mão de obra, aprendendo a lidar com as novas tecnologias de produção, mas não deveria ter autonomia sobre o próprio pensamento ou questionar a organização social vigente.

Em uma sociedade na qual o negro nunca foi, de fato, inserido, é extremamente arriscado discutir uma tradição de autores negros, principalmente se forem considerados os moldes que esta sociedade excludente definiu como parâmetros para

avaliar o que, de fato, merece o status de produção cultural ou, neste caso específico, produção literária, que merece ser lida deixando o legado cultural negro às margens dos mecanismos de prestígio e circulação simbólicos. De fato, para que seja lido e sua obra circule e esteja acessível a seu público leitor, o autor negro deve atravessar o primeiro "filtro", aquele do mercado editorial, como aponta Cuti:

as editoras, por exemplo, têm o que chamam de "linha editorial", demarcadora dos parâmetros de suas exigências para os que nela procuram a publicação de seus escritos. Essa "linha" norteia a(s) mensagem(ns) a ser(em) veiculada(s) de forma impressa e em determinados formatos. Assim como existe a tal "linha" orientando o crivo (a escolha) entre os títulos a serem publicados ou não, também, posteriormente, haverá a seleção do que, estando disponível no mercado, deve receber o aval da publicidade ou da cumplicidade dos meios de comunicação e do Estado para redundar em leitura. ${ }^{16}$

CUTI. Literatura negro-brasileira,

Apesar da grande importância de antologias e grupos editoriais criados e mantidos por e para negros, é inegável o impacto que grandes editoras possuem no mercado editorial brasileiro, ${ }^{17}$ impacto esse que não se resume apenas à possibilidade de publicação, que pode se dar de outras maneiras, mas também reflete na visibilidade e circulação das obras e, consequentemente, dos discursos que carregam. O
17. A este respeito, consultar a quarta leitura no Brasil (2016). edição da pesquisa Retratos da 
18. CUTI. Literatura negro-brasileira, $\mathrm{p}$ 27-28.

19. A este respeito, conferir SOVIK, Liv. Aqui ninguém é branco. Rio de Janeiro: Aeroplano, 2009. atual panorama, realçado pela relativa escassez de publicações autorais de contos e romances afro-brasileiros, demonstra as dificuldades de absorção que o produtor desta literatura encontra diante do nosso mercado editorial. Para publicar e ser visível, o autor negro, muitas vezes, precisa também construir seus circuitos editorais:

a possibilidade da perspectiva negro-brasileira na literatura tinha, assim, seu limite na recepção. Como um dado da realidade, a recepção que se estabelecia impunha, previamente, seu código de aceitabilidade. [...] Ameaçar a predominante concepção de hierarquia das raças seria uma ousadia não admissível. ${ }^{18}$

Apesar de a afirmação de Cuti se referir aos processos de produção e circulação literária do século XIX, o mercado editorial não sofreu mudanças profundas no que se refere à aceitabilidade de um discurso que afronte a hierarquia discursiva enraizada. ${ }^{19}$ A veiculação de um discurso afro-centrado encontra restrições no filtro ideológico do mercado editorial brasileiro, o que praticamente obriga os autores negros a se organizarem em coletivos editoriais que fomentem seus ideais.

\section{PERÍODOS DE PUBLICAÇÃO}

No século XIX, momento em que a ideia de literatura brasileira começa a tomar forma, houve 11 publicações individuais de contos afro-brasileiros e 10 romances afro-brasileiros publicados, contudo, por cinco autores: Francisco de Paula Brito, José do Patrocínio, Machado de Assis, Maria Firmina dos Reis e Antônio Gonçalves Crespo. Nesse período, faz-se necessário lembrar que as publicações de contos e romances ocorriam, majoritariamente, em jornais.

Citar dados biográficos dos autores negros que publicaram obras autorais de conto e romance durante o século XIX torna-se relevante visto o pioneirismo na construção de uma tradição de contistas afro-brasileiros. Este pioneirismo também se estende aos espaços de publicação que tiveram de ser criados pelos próprios autores, uma vez que muitos não encontravam espaço nas casas e veículos editoriais existentes. Não é possível dissociar, neste caso, os produtores, os seus produtos e o contexto histórico no qual estavam inseridos. Francisco de Paula Brito, por exemplo, ajudante de farmácia, tornou-se aprendiz de tipógrafo e trabalhou no Jornal do Comércio, sendo considerado o primeiro ativista a inserir no debate político-editorial a questão racial. Por isso, muitos o consideram o precursor da imprensa negra. Paula Brito foi ainda o primeiro editor de Machado de Assis.

Machado de Assis, por sua vez, trabalhou como aprendiz de tipógrafo na Imprensa Nacional e foi revisor e colaborador no Correio Mercantil, além de ser um dos fundadores da Academia Brasileira de Letras. Entre Paula Brito e Machado 
de Assis é possível perceber uma relação de proximidade que permitiu que seus discursos tivessem certa projeção, além de terem vivido no Rio de Janeiro, local onde se concentrava a maior parte da imprensa brasileira do século XIX.

José do Patrocínio era filho de Justina do Espírito Santo, negra escravizada, e João Carlos Monteiro, vigário da paróquia de Campos dos Goytacazes e orador sacro de reputação na Capela Imperial. Apesar de nunca ter reconhecido a paternidade, João Carlos Monteiro encaminhou José do Patrocínio para sua fazenda em Lagoa de Cima, onde ele passou a infância como liberto, tendo obtido, aos 14 anos, autorização do pai para ir morar no Rio de Janeiro, onde ingressou, em 1874, na Faculdade de Medicina. Além de sua atuação no campo da saúde, José do Patrocínio dedicou-se à carreira de jornalista, participando de importantes periódicos como Os Ferrões, Gazeta de Notícias e A cidade do Rio. Fundou, ainda, a Sociedade Brasileira contra a Escravidão e articulou a Confederação Abolicionista, sendo importante figura em movimentos abolicionistas e republicanos.

Maria Firmina dos Reis nasceu e viveu no estado do Maranhão, tendo trabalhado como professora de primeiras letras. Redigiu Úrsula, primeiro romance abolicionista brasileiro e um dos primeiros romances produzidos por uma mulher no Brasil. Por colaborar em jornais literários, sendo provavelmente sócia-colaboradora da Revista Maranhense,
Maria Firmina conseguiu obter espaço para publicar o conto autobiográfico “A escrava”. Quanto a Antônio Gonçalves Crespo, apesar de ter nascido em terras brasileiras, viveu e publicou em Portugal.

No século XIX, talvez seja adequado afirmar que a literatura afro-brasileira deu-se enquanto manifestações esparsas e em estreita ligação com o jornalismo. Segundo Roger Bastide (1973), os jornais publicados a partir das décadas finais do oitocento brasileiro procuravam, primeiramente, agrupar os homens de cor, dar-lhes senso de solidariedade, encaminhá-los, educá-los a lutar contra o complexo de inferioridade, superestimando seus valores, além de exaltarem a importância de seus eventos e agremiações sociais. Esta tendência prossegue até as duas primeiras décadas do século XX, quando a chamada Imprensa Negra paulista se solidifica.

No período que compreende o início do século XX ao ano de 1945, foram publicados quatro livros de contos, sendo dois de autoria de Raul Astolfo Marques, maranhense, nascido durante a vigência do regime escravocrata. Marques ingressou como servente na Biblioteca Pública do Estado do Maranhão e só conseguiu se estabelecer nos meios literários locais após colaborar em publicações nos diversos órgãos da imprensa.

O período conta, também, com uma publicação de autoria de Machado de Assis e uma publicação de Lima Barreto, cujo 
texto denuncia de forma contundente a corrupção da elite e o preconceito racial e social que também o atingiu.

Quanto aos romances publicados, temos 10publicações duas de Machado de Assis, quatro de Lima Barreto, duas de Arlindo Veiga dos Santos, uma de Nascimento Moraes e uma de Raymundo de Souza Dantas.

É preciso reafirmar que a produção literária afro-brasileira foi afetada em grande medida pela implementação do Estado Novo, embora seja possível dizer que todos os anos em que Vargas esteve no poder foram terríveis para este coletivo populacional.

Durante 15 anos seguidos, Getúlio Vargas governou o país de forma contínua (1930-1945), provocando inúmeras alterações sociais e econômicas, as quais se agravaram no Estado Novo (1937-1945), como a suspensão da Constituição em vigor, o fechamento do Congresso Nacional, a nomeação de interventores estaduais e a criação de um Departamento de Imprensa e Propaganda (DIP) para censurar os meios de comunicação e construir uma imagem positiva do governo manipulando a opinião pública.

Durante a Era Vargas, também foram colocadas em prática diversas estratégias para alcançar o branqueamento progressivo da população brasileira, como a recusa de imigrantes negros, japoneses e judeus, que se distanciavam do perfil de "imigrante desejável” almejado pelo governo, conforme aponta Hagg, em "Os indesejáveis". O desejo de branqueamento da população brasileira não estava, contudo, ligado apenas ao clareamento da pele, mas também à afirmação de uma identidade o mais próxima possível dos padrões europeus, tanto estéticos quanto culturais. ${ }^{20}$

Exemplo de golpe duro no desenvolvimento literário dos negros no Brasil foi a dissolução, em 1937, da Frente Negra Brasileira, maior organização de negros no período, com caráter nacional e de reivindicação de direitos sociais e políticos (iguais) para todos, independentemente da cor da pele. ${ }^{21}$ A organização viu extinto o seu periódico, $A$ Voz da Raça, cujo conteúdo abrangia aspectos sociais, debates sobre identidade e condição econômica da população negra e literatura. ${ }^{22}$ Pode-se dizer que, ao garantir o branqueamento idealizado, o governo tentou sufocar os discursos de resistência, perseguindo as organizações negras e apagando seus traços identitários.

Entre os anos de 1946 e 1978, houve a publicação de cinco livros de contos e seis romances, o que se explica pelo esvaziamento das condições de produção literária da população negra brasileira e pelo início da ditadura militar, em 1964, a qual também perseguiu com veemência iniciativas culturais desta população. Assim como a imprensa, todo e qualquer discurso artístico estava sujeito à censura. Foi
20. A este respeito, sugere-se consultar CAPELATO, Maria Helena. O Estado Novo: o que

Civilização Brasileira, 2007.

21. Ver BARBOSA, Marcio. Frente Negra Brasileira (depoimentos). Săo Paulo-SP. Imprensa Oficial do Estado de São Paulo, 2012

22. A este respeito, conferir FERRARA Miriam Nicolau. A imprensa negra paulista (1915-1963). São Paulo: FFLCH/USP, 1986. 
23. RELATÓRIO da Comissão da Verdade referente à perseguição à população e ao Movimento Negro, [s.p.]. criada a Divisão de Censura de Diversões Públicas (DCDP), que analisava e liberava (ou não) a circulação ou execução de obras. Os parâmetros utilizados pelos censores baseavam-se nos "valores morais e bons costumes", uma espécie de eufemismo para designar qualquer discurso contrário ao regime estabelecido.

De acordo com o Relatório da Comissão da Verdade referente à perseguição à população e ao Movimento Negro,

a oposição ao golpe militar no Brasil não se limitou a setore da classe média urbana de maioria étnica branca; a presença negra no movimento de combate ao regime foi também expressiva. Dentre os mortos e desaparecidos figuram nomes de militantes de origem negra. Afora isso, por serem maioria entre os mais pobres, os negros eram os maiores atingidos pelas políticas autoritárias do período. ${ }^{23}$

Tais políticas autoritárias buscavam reprimir toda e qualquer organização que visasse à igualdade de direitos sociais e políticos, independentemente da cor da pele. Estas políticas escondiam-se, muitas vezes, sob o pretexto de que os discursos de movimentos negros e intelectuais que denunciavam o racismo existente estavam, na verdade, incitando o socialismo no país. Atores, autores, jornalistas e cantores negros sofreram todo tipo de censura. Apesar de ter se intensificado nos anos, a ditadura militar não inventou a perseguição ao movimento negro, tampouco a censura - oficial ou não. Lembremos do Teatro Experimental do Negro (TEN), criado por Abdias do Nascimento em 1945, dissolvido em 1961, que foi impedido pelo governo brasileiro de participar de festivais internacionais de teatro, e sofreu censura em 1951, com a peça "Sortilégio - o mistério negro", do próprio Abdias do Nascimento. ${ }^{24}$

O reduzido número de publicações no período de 1901 a 1978 é apenas um dos reflexos de uma política herdeira do pensamento colonial, segundo a qual, nas palavras de Florentina Souza, "aos negros, africanos ou afrodescendentes [...] não caberia escrever, publicar ou mesmo falar de si ou de seu grupo". ${ }^{25} \mathrm{O}$ resultado desta postura, segundo Souza, é a intimidação de publicações literárias e demais produções culturais a partir da dura perseguição e da censura.

Percebemos, nestes dois últimos períodos citados, uma tentativa por parte do escritor negro de revogar aquilo que Cuti classifica como o maior privilégio, "o de poder mergulhar com a sua arte na medula do seu povo, redimi-lo, consolá-lo e sobretudo lutar com ele" ${ }^{26}$ Calar a voz do negro brasileiro é uma estratégia eficaz para branquear o Brasil não apenas fisicamente, mas também cultural e editorialmente,
24. RELATÓRIO da Comissão da Verdade referente à perseguição à população e ao Movimento Negro, [s.p.].

25. SOUZA. Literatura Afro-Brasileira: algumas reflexões, p. 65.

26. CUTI. Literatura negra brasileira: notas a respeito de condicionamentos, p. 22. 
27. CUTI. Literatura negra otas a respeito de condicionamentos, p. 22 impondo o que será dito, como será dito e, principalmente, por quem será dito.

Finalmente, entre 1979 e o primeiro semestre de 2016 houve um significativo aumento de publicações autorais de contos afro-brasileiros, totalizando 67 livros, bem como das publicações de romances, que totalizaram 39 publicações. Como destaca Cuti, "em 1978 surgiram os 'Cadernos Negros', primeira tentativa de agrupamento, de literatos e aspirantes, em torno de uma publicação coletiva [...] Os nomes aumentam e a aproximação se efetua, e com ela os debates" ${ }^{27}$ Desta forma, o surgimento dos Cadernos Negros, série criada pelo grupo Quilombhoje e que publica anualmente volumes de prosa ou poesia, foi fundamental para o agrupamento dos produtores da chamada literatura afro-brasileira, possibilitando críticas e discussões no intuito de romper com os valores estéticos vigentes, que tratavam a produção do negro brasileiro como algo menor, resultando no que o autor denomina como "autocensura". A série possibilitou a abertura de espaço para que os contistas publicassem, posteriormente, livros individuais, com destaque para o romance e o conto.

Mais uma vez, os negros brasileiros organizavam-se em quilombos, agora editoriais, para conseguir produzir, divulgar e ter acesso a elementos relativos à própria cultura e história. Apenas o surgimento de editoras e grupos editoriais criados e compostos por e para negros permitiria o rompimento com o modelo imposto e mantido pelo controle dos meios de publicação que existiam até então e, de certa forma, "filtravam" a criação artística.

Em seu primeiro número, a proposta do coletivo não deixa margem a questionamentos:

Estamos no limiar de um novo tempo. Tempo de África, vida nova, mais justa e mais livre e, inspirados por ela, renascemos arrancando as máscaras brancas, pondo fim à imitação. Descobrimos a lavagem cerebral que nos poluía e estamos assumindo nossa negrura bela e forte. Estamos limpando nosso espírito das ideias que nos enfraquecem e que só servem aos que querem nos dominar e explorar. ${ }^{28}$

Este novo movimento cultural literário não aceitava ou buscava meramente reproduzir o discurso etnocêntrico vigente; ao contrário, deseja promover e revelar autores negros, que se assumem e escrevem como negros. Esta iniciativa foi vital para o fortalecimento da literatura afro-brasileira, em especial no que diz respeito não só à poesia e ao conto, mas também ao romance. Isso sem contar a contribuição de iniciativas como as séries literárias para a formação de um público leitor também negro. Autores como Abelardo Rodrigues, Abílio Ferreira, Ademiro Alves (Sacolinha), Conceição Evaristo, Cristiane Sobral, Esmeralda Ribeiro Geni Guimarães, Henrique Cunha Jr., Lande Onawale, Lia
28. CUTI et al. (Org.). Cadernos negros 1, [s.p.]. 
Vieira (Eliana Vieira), Miriam Alves, Paulo Colina, Ramatis Jacino e Waldemar Euzébio Pereira, após publicarem em antologias de contos da série Cadernos Negros, escreveram livros individuais de contos e/ou romances, reforçando a contribuição dos meios de resistência literária negra para a formação de uma geração de autores para além dos espaços coletivos.

\section{CASAS EDITORIAIS}

Mesmo tendo o levantamento apontado apenas 88 livros de contos publicados, estes ocorreram por meio de 55 casas editoriais distintas, já os 61 romances foram publicados em 56 editoras.

Em cinco das publicações, a edição é do próprio autor Pela Mazza Edições, saíram sete livros de contos e dois romances. Cinco foram os livros de contos publicados pela Editora Garnier e cinco os romances. As casas editoriais Ciclo Contínuo, Nandyala, Pallas e Paulinas lançaram três obras autorais de contos, cada uma delas. O Jornal do Comércio publicou três livros de contos, os quais haviam anteriormente ocupado as páginas do periódico. Casas editoriais como Editora do Brasil, EDUFBA, FTD, GRD, Grupo Editorial Rainha Ginga e Ilustra publicaram, individualmente, dois livros autorais de contos; Ciência Moderna, Mazza, Record, Rocco, Salesiana e ZFM Editora publicaram dois romances no período analisado.
Agir, Anima, Arte Risco, Bertrand, Blackitude, Bluhm, CCM Editora, Centro Cultural “Teresa D'Ávila”, CL Edições, CODECRI, Corrupio, Crisálida, Dandara, Difusão Cultural do Livro, Dulcina Editora, Edições Populares, EDICON, Editora Malê, Editora SM, Folha Seca, Fundação Nestlé de Cultura, Gianlorenzo Schettino, José Olympio, Laemmert \& Co. Editores, Livraria Lombaerts \& C., Martins, Odorizzi, Oduduwa, Quarto Setor Editorial, Quilombhoje, Record Relume-Dumará, Revista Maranhense, Scipione, Scortecci, Secretaria de Cultura da Bahia, Selo Negro, SIOGE, Sobá, Terceira Margem e Vozes foram responsáveis por publicar uma obra de conto cada. Agir, Appris, Babel, Bertrand Brasil, Biblioteca 24 horas, Borboletas, Centro Culturall Nascimento de Moraes, Companhia das Letras, Confraria do Vento Editora, Córrego, Dandara Gráfica Editora, Divine Edition, Livraria do Globo, Edicel, Edifurb, Editora Globo, Editora Mulheres, Editora Vitória, Estação Liberdade, G. Viana \& C Gazeta de notícias, Irmão di Giorgio, Jacintho Ribeiro dos Santos Editor, Língua Geral, Mérito, Nankim, Notrya, Nova Letra, Officinas d' A Noite, Ogum's Toques Negros, Pallas, Parelelo 27, Paris: Garnier, Planeta, Prefeitura de Salvador, Quilombhoje, Scortecci, Selo Editorial RG, Selo Negro, bem como as tipografias Editores Gomes de Oliveira \& C. Tipografia do Globo, Francisco Alves, Tipografia Nacional, Tipografia Revistas Tribunais, Tipografia São Judas Tadeu, Typografia da Gazeta da Tarde e Typographia do Progresso, 
29. Não foi possível precisar qual o meio de publicação de sets obras: Enterro, de Abelardo Rodrigues: Sertão sinistro, de Aristides Teodoro; Trajetória cotidiana, de Bahia (José Ailton Ferreira); Os retirantes, de José do Patrocínio Contos para nossos filhos, de Antônio Gonçalves Crespo e $A$ vid maranhense e Natal (quadros), foram responsáveis pela publicação de um romance cada uma delas.

Apenas duas casas editoriais publicaram ao menos cinco livros de contos, enquanto 40 publicaram apenas um livro autoral de conto e apenas uma publicou ao menos um romance, enquanto 48 publicaram apenas um romance. ${ }^{29}$

Este cenário sugere três características desta linhagem literária. Em primeiro lugar, felizmente, a partir das décadas finais do século $\mathrm{XX}$, surgem editoras cuja prioridade é a escrita afro-brasileira; em segundo, significativa maioria destas editoras publica autores negros, embora não se possa assegurar a predominância ou a preocupação com o desenvolvimento de catálogo capaz de garantir espaço a estes autores; em terceiro, a autopublicação é um fenômeno corrente e pouco estudado neste segmento literário.

Esses dados reforçam o cenário de dificuldades de absorção dos produtores de literatura afro-brasileira, uma vez que as grandes editoras quase não publicaram autores negros, o que fez com que eles se tornassem, em grande medida, "editores" que criam caminhos para a autopublicação. Autores como Francisco de Paula Brito e Machado de Assis, pioneiros na publicação de contos afro-brasileiros, tiveram de se estabelecer nos meios de comunicação da época e, de certa forma, "firmar" o próprio nome na imprensa local antes de serem publicados por casas editoriais, como a Garnier. Ou seja, foi necessário que os autores se inserissem em determinada esfera intelectual e social da época para, então, alcançarem o direito à voz. Este cenário parece pouco modificado nos dias atuais. Boa parte dos autores da chamada "geração Cadernos Negros”, como Cuti, Conceição Evaristo, Mirian Alves, Esmeralda Ribeiro, Márcio Barbosa, Oswaldo de Camargo, entre outros, seguiram os passos de seus precursores. A série literária abriu-lhes caminhos, ajudou-os a formar público leitor. Talvez por isso estes escritores tenham se arriscado a publicar individualmente com alguma frequência.

Dentre as demais editoras que também publicaram mais de um livro destacam-se aquelas denominadas "editoras de nicho", neste caso, voltadas para produtores de literatura afro-brasileira e leitores que desejam ter acesso a obras que abordem e valorizem aspectos da cultura afro-brasileira, como é o caso da Ciclo Contínuo Editorial, do Grupo Editorial Rainha Ginga, da Mazza Edições e da Nandyala. É neste sentido que reiteramos a organização dos produtores culturais afro-brasileiros por meio do que chamamos de "quilombos editoriais", isto é, iniciativas organizadas com a finalidade de discutir, produzir e fazer circular obras pautadas em uma estética afro-brasileira, ao mesmo tempo que resistem à configuração dos catálogos etnocêntricos que compõem o mercado editorial brasileiro. 
Curioso é o fato de que mesmo nas casas editoriais especializadas em cultura afro-brasileira, como Pallas, Selo Negro, Quilombhoje, Mazza e Nandyala, a presença destes romances no catálogo é baixa, talvez por questões mercadológicas, dada a dificuldade de colocar em circulação grandes quantidades de narrativas desta natureza. Ainda há que se considerar a dificuldade de distribuição deste material. As demais editoras pouco levam em conta um catálogo especificamente voltado ao romance afro-brasileiro, mesmo com a vigência da Lei n. 10.639, embora aqui e ali publiquem livros deste gênero.

Nos casos em que uma casa editorial possui apenas uma publicação, é provável se tratar de edições realizadas por meio de recursos do próprio autor, pois este tende a procurar nos selos ou marcas editoriais uma forma de melhor aceitação de seu livro no mercado. Contudo, para confirmar tal hipótese, são necessárias pesquisas específicas, o que excederia os objetivos deste trabalho e o tempo disponível para sua realização.

\section{LOCAIS DE PUBLICAÇÃO}

Das 88 publicações de contos, 28 aconteceram na cidade do Rio de Janeiro; 24 na cidade de São Paulo; e 13 na cidade de Belo Horizonte. Em Salvador, foram publicados cinco livros de contos. Em Porto Alegre e Santos, ocorreram duas publicações em cada uma das cidades. Nas cidades de Blumenau, Brasília, Lorena, Petrópolis e São Luís foi localizada a publicação de apenas um livro de conto em cada uma.

Dos 61 romances publicados, 34 ocorreram na cidade do Rio de Janeiro; 14 em São Paulo e quatro em Salvador. Em Belo Horizonte, Blumenau, Florianópolis e São Luís, ocorreram duas publicações por cidade. Nas cidades de Campinas, Curitiba, Porto Alegre e Santos foi localizado apenas um romance publicado em cada uma delas. ${ }^{30}$

Observamos, nessa distribuição, a concentração de publicações no eixo RJ-SP, um provável reflexo da concentração de renda no país, que não sofreu profundas modificações no modelo distributivo, sobretudo de bens simbólicos, mesmo quando consideramos dados de trabalhos mais otimistas, como o de Barros, Foguel e Ulysses. ${ }^{31}$ Vivendo, atualmente, o que Milton Santos denomina "globalização perversa", ${ }^{32}$ percebemos, ainda, que, mesmo após todo o período transcorrido desde o Brasil colônia até os dias atuais, a relação entre dinheiro e informação permaneceu inabalada em seus aspectos fundamentais.

Essa concentração de publicações, ao mesmo tempo que pode ser lida como locais em que houve a ruptura com o silenciamento imposto de forma massiva, também pode ser lida como uma espécie de facilitador do controle daquilo que é produzido, pois, como explica Milton Santos, "é desse modo
30. Não foi possivel determinar a cidade onde se deu a publicação de oito títulos, pois esta informação não estava contida nas fichas catalográficas.

31. BARROS; FOGUEL; ULYSSES. Desigualdade de renda no Brasil: uma análise da queda recente.

32. SANTOS. Por uma outra globalização. 
33. SANTOS. Por uma outra globalização, p. 39. que a periferia do sistema capitalista acaba se tornando ainda mais periférica, seja porque não dispõe totalmente dos novos meios de produção, seja porque lhe escapa a possibilidade de controle". ${ }^{33}$

A manutenção das zonas periféricas, numa relação de causa-efeito com a manutenção de um eixo central, propicia tal controle da informação, que é um dado imprescindível e essencial para garantir certo grau de autonomia ao indivíduo. $\mathrm{O}$ próprio critério para definir o que deve ou não ser lido, ou o que pode ou não receber o status de "obra literária" passa pelas zonas metropolitanas, ou, neste caso, o eixo Rio-São Paulo, que dita os discursos preferenciais que devem ser ouvidos à custa do esquecimento dos demais. Não que o histórico de movimentos e organizações que lutaram pela igualdade de direitos sociais e políticos, independentemente da cor da pele nestes estados, São Paulo e Rio de Janeiro, deva ser anulado, apenas faz-se necessário questionar a distribuição de casas editoriais ao longo do espaço geopolítico brasileiro.

\section{CONSIDERAÇÕES FINAIS}

A palavra-chave para compreender as manifestações culturais afro-brasileiras é resistência. Estudar quais e como se tornaram possíveis as publicações individuais de contos afro-brasileiros, a despeito das tiranias estabelecidas pelas grandes mídias, que, de certo modo, mantêm grande parte do controle da informação e do dinheiro, bem como os seus reflexos na comunidade negra brasileira ao longo da história, é um dos caminhos para compreender o impacto provocado pela organização negra, funcionando como elo entre produtores e público.

De modo geral, analisar qualitativamente os dados quantitativos referentes às produções individuais de livros de contos e romances afro-brasileiros reforça a importância da resistência negra na literatura como forma de se opor ao etnocentrismo vigente também no campo editorial. Se por um lado há poucos autores negros com publicações individuais nos dois gêneros, por outro lado é possível apontar para a dificuldade enfrentada pelo autor negro quando o assunto é a publicação individual.

O gênero conto é mais numeroso do que o romance. Isso se deve à maior facilidade de publicação e circulação daquele em detrimento deste.

Houve concentração de publicações no sudeste do país, como esperado. O eixo RJ-SP concentra a maio parte das editoras e, logo, das produções editoriais, ainda que independentes.

Pudemos perceber que a maioria das casas editoriais estudadas não tem uma linha editorial voltada à literatura afro-brasileira. Há, sim, editoras especializadas, como Pallas, 
Mazza, Selo Negro, Nandyala. Porém, o catálogo de romances ainda está por se desenvolver, ao passo que o de contos está em processo de ampliação.

Do ponto de vista cronológico, embora os dois gêneros tenham se iniciado no século XIX, no Brasil, e ganhado notoriedade no início do século XX, houve interrupções drásticas durante os períodos ditatoriais vividos pelo país. Contudo, a partir das décadas finais do século passado, os dois gêneros começaram um processo de amplo desenvolvimento. Pode-se dizer, portanto, que o romance e o conto afro-brasileiros resistem e persistem na nossa história literária, embora estejam ambos em processo de afirmação e consolidação no cenário contemporâneo.

Escrever e ser lido constitui, antes de qualquer outra coisa um ato de poder, uma forma de atuar efetivamente na realidade e, dada a forte tradição escrita instituída no Brasil, um instrumento para inscrever de forma perene a memória de determinado grupo na história da nação.

A história editorial do conto e do romance afro-brasileiro não se esgota neste trabalho, que se dedicou apenas a traçar um panorama de tais publicações e, mais especificamente, das iniciativas individuais. Esperamos ter obtido êxito na proposta de abrir espaço para questionamentos acerca dos ecos e dos silêncios provocados pelas vozes dos contistas e romancistas afro-brasileiros no nosso mercado editorial. Pensar a literatura afro-brasileira é pensar, antes de tudo, como se deu a inserção do negro, enquanto indivíduo e sujeito, nos percursos constituintes da sociedade brasileira. Desvendar as configurações editoriais de uma literatura na qual o negro enuncie sua vivência a partir de dentro é, acima de tudo, um ato "quilombola" de resistência.

\section{REFERÊNCIAS}

BARROS, Ricardo Paes de; FOGUEL, Miguel Nathan; ULYSSES, Gabriel. Desigualdade de renda no Brasil: uma análise da queda recente. Brasília: IPEA, 2006

BASTIDE, Roger. Estudos afro-brasileiros. São Paulo: Perspectiva, 1973

CENTRO de Pesquisa e Documentação de História Contemporânea do Brasil (CPDOC). Disponível em: <http:// cpdoc.fgv.br/>. Acesso em: 04 mar. 2016

CUTI, Luiz Silva. Literatura negro-brasileira. São Paulo: Selo Negro, 2010

CUTI, Luiz Silva. Literatura negra brasileira: notas a respeito de condicionamentos. In: QUILOMBHOJE (Org.). Reflexões sobre literatura afro-brasileira. São Paulo: Conselho de Participação e Desenvolvimento da Comunidade Negra, 1985. p. 15-24.

CUTI, Luiz Silva et al. (Org.). Cadernos negros 1. São Paulo: Ed. dos autores, 1978. 
DUARTE, Eduardo de Assis. Literatura afro-brasileira: um

conceito em construção. Estudos de Literatura Brasileira

Contemporânea, Brasília: UnB, n. 31, p. 11-23, jan.-jun. 2008.

HAGG, Carlos. Os indesejáveis. 2012. Disponível em: <https:// goo.gl/MvdKd2 >. Acesso em: 12 out. 2015

MARTINS, Leda Maria. Literatura e afro-descendência. In:

PEREIRA, Edimilson de Almeida (Org.). Um tigre na floresta de

signos: estudos sobre poesia e demandas sociais no Brasil. Belo

Horizonte: Mazza, 2010. p. 107-131.

RELATÓRIO da Comissão da Verdade referente à perseguição à população e ao Movimento Negro. Disponível em: < https://goo. gl/tzLm2j>. Acesso em: 20 out. 2015.

SANTOS, Milton. Por uma outra globalização. 24. ed. Rio de Janeiro: Record, 2015.

SILVA, Geraldo: ARAÚJO, Márcia. Da interdição escolar às ações educacionais de sucesso: escolas dos movimentos negros e escolas profissionais, técnicas e tecnológicas. In: ROMÃO, Jeruse (Org.). História da educação do negro e outras histórias Brasília: Ministério da Educação, Secretaria de Educação

Continuada, Alfabetização e Diversidade, 2005. p. 65-78.

SOUZA, Florentina. Literatura Afro-Brasileira: algumas reflexões. Revista Palmares: Cultura Afro-Brasileira, n. 2, p. 64-72, dez. 2005 